\title{
Effects of Strain, Novelty, and NMDA Blockade on Auditory-Evoked Potentials in Mice
}

\author{
Steven J Siegel*, 1,2,3, Patrick Connolly ${ }^{1,2}$, Yuling Liang ${ }^{1,2}$, Robert H Lenox ${ }^{3}$, Raquel E Gur ${ }^{2}$, Warren B \\ Bilker $^{2,4}$, Steven J Kanes ${ }^{2}$ and Bruce I Turetsky ${ }^{2}$ \\ 'Stanley Center for Experimental Therapeutics, University of Pennsylvania, Philadelphia, PA, USA; '2Division of Neuropsychiatry, University of \\ Pennsylvania, Philadelphia, PA, USA; ${ }^{3}$ Molecular Neuropsychopharmacology Program, Department of Psychiatry, University of Pennsylvania, \\ Philadelphia, PA, USA; ${ }^{4}$ Department of Biostatistics and Epidemiology, University of Pennsylvania, Philadelphia, PA, USA
}

\begin{abstract}
People with schizophrenia exhibit impaired ability to modify electroencephalographic event-related potential (ERP) responses to novel stimuli. These deficits serve as a window into the abnormalities of neuronal organization and function and are thought to reflect a component of genetic vulnerability for schizophrenia. We describe differences among inbred mouse strains for ERPs following a novelty detection paradigm, as a model for genetic contributions to disease vulnerability. Auditory-evoked potentials were recorded during an auditory oddball task in nonanesthetized C57BL/6J, $\mathrm{C} 3 \mathrm{H} / \mathrm{HeJ}$, and DBA/2J mice prior to and following ketamine (I0 mg/kg). Stimuli consisted of 80 sets of 24 standard tones followed by one novel tone. Principal component analysis yielded four temporal components that contribute to the auditory ERP responses to standard and novel stimuli. Two principal components that varied between standard and novel stimuli also differed among inbred mouse strains. Post hoc analyses indicate that strain effects on novelty detection are due to a significant difference between the response to novel and standard tones in $\mathrm{C} 3 \mathrm{H} / \mathrm{HeJ}$ mice that is absent in the other two strains. Inbred strains of mice vary in their ability to perform neuronal detection of change in the auditory environment. The ability to model novelty detection deficits in mice will aid in identifying genetic contributions to abnormal neuronal organization in people with schizophrenia.

Neuropsychopharmacology (2003) 28, 675-682. doi:10.1038/sj.npp. 1300087
\end{abstract}

Keywords: auditory evoked potentials; mouse; schizophrenia; ketamine; p300

\section{INTRODUCTION}

Sensory event-related potentials (ERPs) have been widely used to examine basic neuronal activity in both normal brain function and disease-related impairments. Such electroencephalographic ERP measures have been studied extensively in schizophrenia, and have revealed abnormalities in the basic processing of both repeated and novel environmental stimuli (Freedman et al, 1983; Shelley et al, 1991; Javitt et al, 1993; Catts et al, 1995; Boutros et al, 1999; Mathalon et al, 2000). Animal models of ERP abnormalities have been developed to assist in examining pharmacological, environmental, and genetic factors that influence impaired profiles seen in people with schizophrenia (Javitt et al, 1996; Leonard et al, 1996; Ruusuvirta, 1999; Pincze et al, 2001). Notable among these models have been studies of the mouse analog of gating of the human P50/N100 ERP

\footnotetext{
*Correspondence: Dr SJ Siegel, Stanley Center for Experimental Therapeutics, Division of Neuropsychiatry, Molecular Neuropsychopharmacology Program, University of Pennsylvania, PA 19104, USA, Tel: + I 215573 0278, Fax: + | 2156627903 ,

E-mail: siegels@mail.med.upenn.edu or turetsky@bbl.med.upenn.edu Online publication: 16 September 2002 at htpp://www.acnp.org/ citations/Npp09 | 60238 |
}

to repetitive auditory stimuli (Stevens et al, 1996). These efforts in mice have resulted in the discovery of straindependent expression of hippocampal P20/N40 gating and the identification of a candidate gene for the phenotype, including the $\alpha 7$-NAChR nicotinic receptor (Leonard et al, 1996).

The ability to detect change in auditory stimulus characteristics is a basic neuronal function that can be measured in humans with ERPs. These include the mismatch negativity, the P300 (also termed P3) and a novelty-elicited component occurring between 400 and $600 \mathrm{~ms}$, termed the slow wave (Ford and Hillyard, 1981; Roth et al, 1981; Sams et al, 1983; Paavilainen et al, 1989; Ogura et al, 1991; Alho et al, 1998; Ceponiene et al, 1998; Escera et al, 1998; Schall et al, 1999; Spencer et al, 2001). Mismatch negativity is an automatic electroencephalographic response to change in stimulus characteristics such as tone or duration. It occurs between 100 and $225 \mathrm{~ms}$ in humans and is viewed as an indicant of early detection of novelty in the environment. Multiple studies have shown that mismatch negativity is reduced in people with schizophrenia, as well as their first-degree relatives, and is disrupted by NMDA antagonists including ketamine in humans and monkeys (Shelley et al, 1991; Javitt et al, 
1993, 1996; Umbricht et al, 2000; Jessen et al, 2001; Siegel et al, 2001). The P300 is an auditory-evoked potential with a latency of approximately $320 \mathrm{~ms}$ that is elicited by changes in stimulus quality and has been shown to differ in people with schizophrenia in both amplitude and latency of the response (Schall et al, 1999; Mathalon et al, 2000; Grzella et al, 2001).

The current study describes the use of mice for the examination of interstrain variation for the amplitude of the novelty-evoked response as well as the effect of NMDA blockade with the noncompetitive NMDA antagonist ketamine. As mice are amenable to both pharmacological and genetic manipulations, this approach is proposed to facilitate candidate gene discovery relevant to schizophrenia. The strains chosen for this first demonstration of novelty ERPs in mice include $\mathrm{C} 3 \mathrm{H} / \mathrm{HeJ}$ mice that display maximal gating of the $\mathrm{P} 20 / \mathrm{N} 40 \mathrm{ERP}, \mathrm{DBA} / 2$ mice that display schizophrenia-like gating of evoked potential responses, and $\mathrm{C} 57 \mathrm{BL} / 6 \mathrm{~J}$ mice that display an intermediate gating profile and serve as the background strain for the majority of transgenic animals of interest in the Mouse Neurobehavioral Genetics Program at the University of Pennsylvania (Stevens et al, 1996).

\section{MATERIALS AND METHODS}

\section{Animals}

Mice were obtained from Jackson Labs (Bar Harbor, ME) at $7-8$ weeks of age, C57BL/6J $(n=10), \mathrm{C} 3 \mathrm{H} / \mathrm{HeJ}(n=14)$, and DBA/2J $(n=12)$. All testing was conducted between 8 and 10 weeks of age.

\section{Surgery}

Animals underwent stereotaxic implantation of tripolar electrode assemblies (PlasticsOne Inc., Roanoke, VA) for nonanesthetized recording of hippocampal auditory-evoked potentials. All protocols were conducted in accordance with University Laboratory Animal Resources (ULAR) guidelines, and are approved by the Institutional Animal Care and Use Committee (IACUC). Animals were anesthetized with ketamine hydrochloride/xylazine $(100 / 10 \mathrm{mg} / \mathrm{kg})$ prior to surgery. Surgical coordinates were measured relative to bregma in the $x, y$, and $z$ dimensions. Three stainless-steel electrodes, mounted in a single pedestal, were aligned along the sagittal axis of the skull at $1 \mathrm{~mm}$ intervals with precut lengths of $3.0 \mathrm{~mm}$ (positive) and $1.0 \mathrm{~mm}$ (ground and negative). Positive electrodes were placed in the CA3 hippocampal region $1.4 \mathrm{~mm}$ posterior, $2.75 \mathrm{~mm}$ lateral, and $2.75 \mathrm{~mm}$ deep relative to bregma. Negative electrodes were placed adjacent to the ipsilateral neocortex at $0.6 \mathrm{~mm}$ anterior, $2.75 \mathrm{~mm}$ lateral, and $0.75 \mathrm{~mm}$ deep relative to bregma. Ground electrodes were located between recording and reference at $0.4 \mathrm{~mm}$ posterior, $2.75 \mathrm{~mm}$ lateral, and $0.75 \mathrm{~mm}$ deep to bregma. The electrode pedestal was secured to the skull with cyanoacrylic cement (PlasticsOne, Roanoke, VA). Following surgery, animals were individually housed and allowed to recover for $24 \mathrm{~h}$ prior to the recording of evoked potentials.

\section{Recording}

Each animal was placed in a sound-attenuated recording chamber (background white noise $70 \mathrm{~dB}$ ) inside a Faraday electrical isolation cage. Electrode pedestals were connected to a $30 \mathrm{~cm}$ tripolar electrode cable that exited the chamber to connect to a high-impedance differential AC amplifier (A-M systems, Carlsborg, WA) set to $1000 \times$ amplification, $1 \mathrm{~Hz} / 500 \mathrm{~Hz}$ band-pass filter. EEG activity was recorded using ERPSYSTEM (Neurobehavioral Laboratory Software, 1991) on a 486-microprocessor computer. Each animal was allowed to explore the chamber for $15 \mathrm{~min}$ prior to recording to habituate to the setting. Stimuli were generated by ERPSYSTEM software and were delivered through a speaker attached to the testing chamber ceiling. Speakers were connected to a model SA-155 audio amplifier (Radioshack, Fort Worth, TX), which was interfaced with the computer. Standard stimuli were pure $1500 \mathrm{~Hz}$ tones of $50 \mathrm{~ms}$ duration at $75 \mathrm{~dB}$ SPL. Novel pitch stimuli were $3000 \mathrm{~Hz}$ tones of $50-\mathrm{ms}$ duration at $75 \mathrm{~dB}$ SPL. Each trial was composed of a train of 24 standard tones followed by one novel tone. The interstimulus interval was $500 \mathrm{~ms}$ between all tones. Electroencephalographic signal was digitally sampled at $1000 \mathrm{~Hz}$, from $40 \mathrm{~ms}$ prior to stimulus onset until $280 \mathrm{~ms}$ after each tone. Following recording of evoked potentials, electrode tips were marked for histological evaluation with deposition of iron around the electrode site. A total of 80 sets of 24 standard and one novel tone were presented. Average waves were created for the novel and the 24th standard tone to keep the trial number constant between conditions. Recordings were conducted prior to and following administration of ketamine $(10 \mathrm{mg} /$ kg) (Figure 1).

\section{Data Analysis}

Four waveforms were obtained from each mouse, including the novel and standard tone responses both before and after ketamine administration. Since there are no previous data regarding the nature of the ERP response to novelty in mice, principal components analysis (PCA) was used to identify components of the auditory ERP response that exhibited variation associated with strain, tone condition, and drug administration. This method was selected since it allows for objective determination of constituent ERP components that contribute to the overall response by deconstructing the wave into portions that vary in conjunction with identified variables. PCA was performed on all 144 baseline-corrected waveforms from 36 mice. Components were retained for further analysis based on the scree plot of eigenvalues. Varimax rotation was performed to maximize loading of factors onto the smallest number of temporal components (Spencer et al, 2001). Repeated measures analysis of variance (ANOVA) was then used to examine the effects of strain, novelty, and ketamine administration on the factor scores, both across all components and separately for each individual component, with strain as the independent variable and stimulus condition (novel $v s$ standard) and ketamine administration (pre $v s$ post) as within-group factors. Significant multivariate or interaction effects were followed by post hoc paired contrasts. 


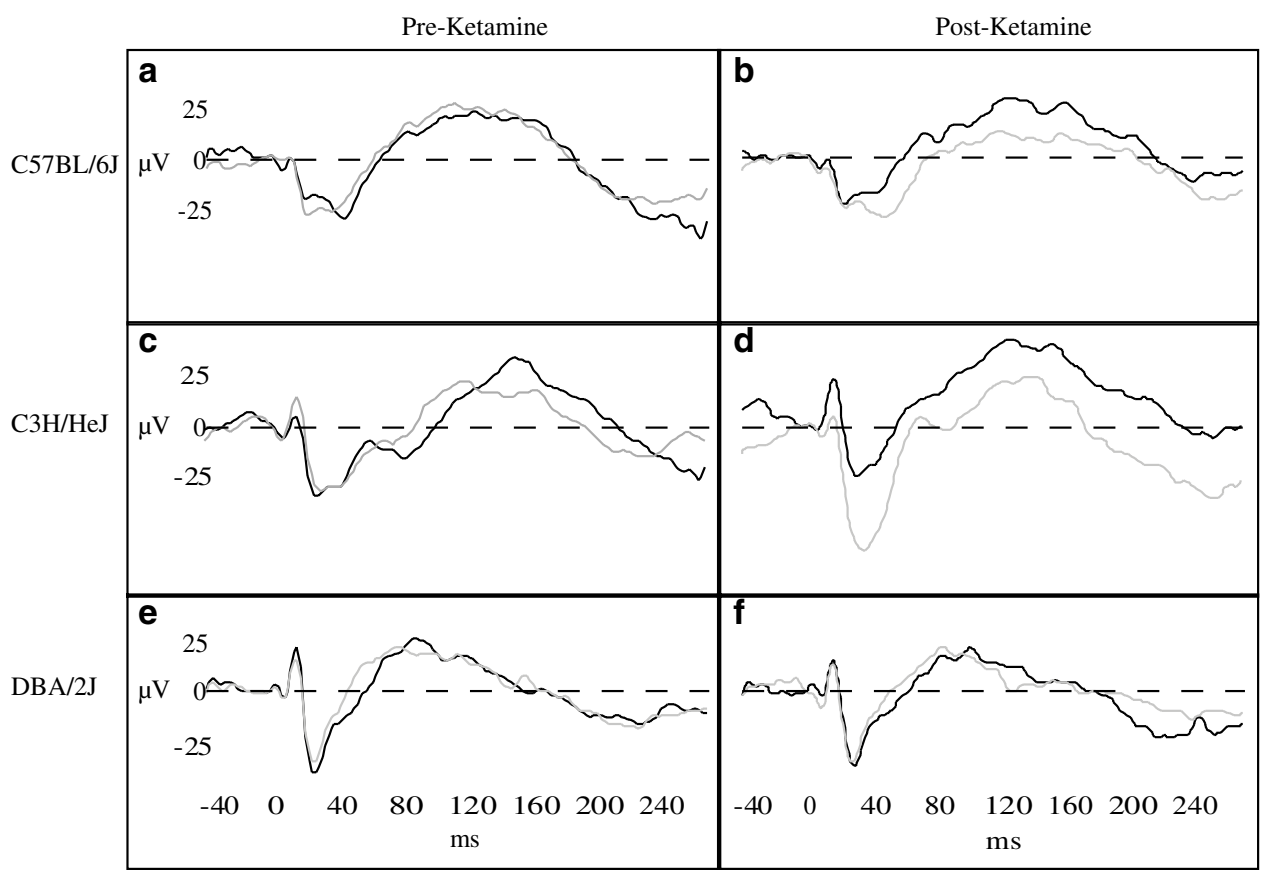

Figure I Grand average auditory-evoked potentials from C57BL/6J (a, b), C3H/HeJ (c, d), and DBA/2J (e, f). (a, c, e) Response to novel (black) and standard (gray) tones prior to administration of ketamine. (b, $d, f$ ) Response to novel (black) and standard (gray) waves following $10 \mathrm{mg} / \mathrm{kg}$ ketamine.

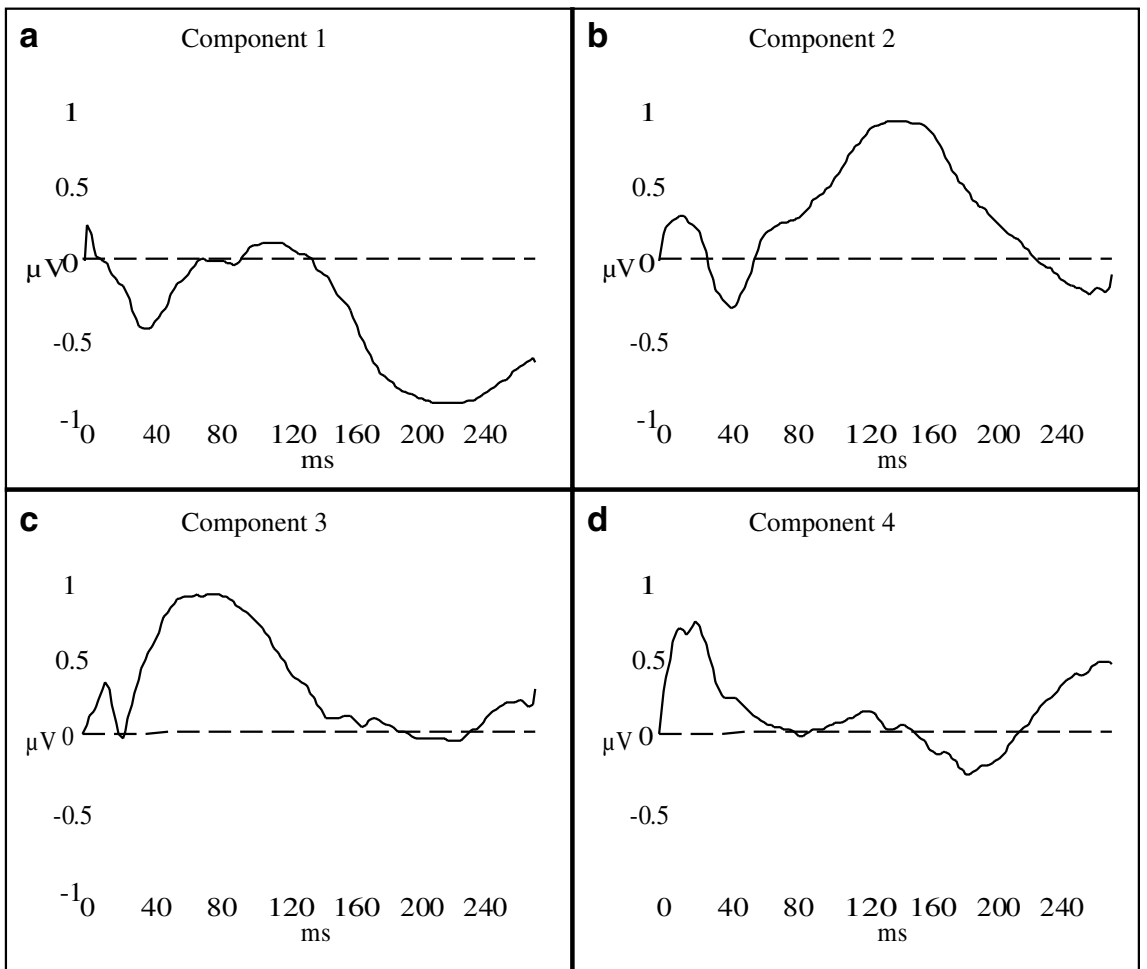

Figure 2 Temporal principal components identified using the scree plot following Varimax rotation: (a) component I, (b) component 2, (c) component 3, and (d) component 4. Time in milliseconds listed on the abscissa with factor load scores on the ordinate.

\section{RESULTS}

Four principal components, accounting for $79 \%$ of the variance, were identified from the scree plot of eigenvalues following factor analysis (Figure 2) (Cattell, 1966; Bentler and Yuan, 1996). Mean factor scores for each strain, tone condition, and drug state are presented in Table 1. The omnibus ANOVA revealed a significant effect of strain across the four components (Wilks' $\lambda(8,60)=0.53$, $p=0.01)$, indicating that the auditory ERP differs among 
Table I Factor Load Scores for Components I-4 for each Condition by Strain, Tone Condition, and Drug

\begin{tabular}{|c|c|c|c|c|c|c|c|c|c|}
\hline \multirow[b]{3}{*}{ Strain } & \multirow[b]{3}{*}{ Factor } & \multicolumn{4}{|c|}{ Pre-ketamine } & \multicolumn{4}{|c|}{ Post-ketamine } \\
\hline & & \multicolumn{2}{|c|}{ Novel } & \multicolumn{2}{|c|}{ Standard } & \multicolumn{2}{|c|}{ Novel } & \multicolumn{2}{|c|}{ Standard } \\
\hline & & Mean & SD & Mean & SD & Mean & SD & Mean & SD \\
\hline \multirow[t]{4}{*}{ C57BL/6] } & I & -0.36 & 0.87 & -0.24 & 0.89 & 0.33 & 0.74 & 0.10 & 0.41 \\
\hline & 2 & 0.17 & 0.71 & 0.09 & 1.11 & 0.20 & 1.35 & -0.16 & 1.47 \\
\hline & 3 & -0.04 & 0.90 & 0.13 & 0.86 & 0.13 & 0.71 & -0.27 & 0.93 \\
\hline & 4 & -0.37 & 0.70 & -0.14 & 0.75 & -0.25 & 1.00 & -0.44 & 0.59 \\
\hline \multirow[t]{4}{*}{$\mathrm{C} 3 \mathrm{H} / \mathrm{HeJ}$} & I & 0.22 & 1.28 & 0.05 & 0.78 & 0.51 & 1.58 & -0.57 & 1.25 \\
\hline & 2 & 0.37 & 0.90 & 0.01 & 1.00 & 0.69 & 1.25 & 0.30 & 0.96 \\
\hline & 3 & -0.64 & 1.08 & -0.40 & 1.06 & 0.11 & 0.92 & -0.47 & 0.76 \\
\hline & 4 & -0.30 & 1.28 & 0.26 & 0.78 & 0.52 & 0.72 & -0.05 & 0.95 \\
\hline \multirow[t]{4}{*}{ DBA/2] } & । & -0.05 & 0.85 & -0.03 & 0.75 & -0.19 & 0.80 & 0.17 & 0.76 \\
\hline & 2 & -0.43 & 0.48 & -0.52 & 0.66 & -0.33 & 0.64 & -0.57 & 0.46 \\
\hline & 3 & 0.39 & 0.93 & 0.59 & 1.31 & 0.23 & 0.75 & 0.46 & 1.06 \\
\hline & 4 & 0.28 & 1.24 & 0.16 & 0.93 & 0.24 & 1.24 & -0.17 & 1.55 \\
\hline
\end{tabular}

the strains. Subsequent paired contrasts indicated that this was due to a difference between $\mathrm{C} 3 \mathrm{H} / \mathrm{HeJ}$ and $\mathrm{DBA} / 2 \mathrm{~J}$ (Wilks' $\lambda(4,30)=0.59, p<0.01)$. This overall strain effect is apparent in the grand average ERP waveforms for the different strains, averaged across all stimulus and drug conditions. There were no significant effects of drug or condition that were evident across all components. Figure 3 demonstrates the ERP waveform for each strain across stimulus conditions and drug treatment. An example of a human auditory ERP is included to provide for comparison of the relative latencies between mouse and human waveforms.

The first temporal component identified by PCA accounted for $28 \%$ of the variance, with peak factor loading between 210 and $240 \mathrm{~ms}$ and with an earlier lower amplitude peak at approximately $40 \mathrm{~ms}$ (Figure 2a). ANOVA of component 1 yielded a significant interaction effect between strain and novelty $(\mathrm{F}(2,33)=3.88, p=0.03)$. This reflected a significant difference between $\mathrm{C} 3 \mathrm{H} / \mathrm{HeJ}$ and $\mathrm{DBA} / 2 \mathrm{~J}$ $(\mathrm{F}(1,33)=7.33, p=0.01)$. Post hoc comparisons indicated a difference between novel and standard responses for $\mathrm{C} 3 \mathrm{H} /$ HeJ mice $(\mathrm{F}(1,33)=9.20, p<0.01)$, but not $\mathrm{C} 57 \mathrm{BL} / 6 \mathrm{~J}$ or DBA/2J.

The second component accounted for $22 \%$ of the overall variance with maximal amplitude at approximately $150 \mathrm{~ms}$ (Figure 2b). A smaller negative deflection was present at approximately $40 \mathrm{~ms}$. ANOVA for component 2 revealed independent main effects for both strain $(\mathrm{F}(2,33)=4.14$, $p=0.02)$ and novelty $(\mathrm{F}(1,33)=6.05, p=0.02)$, with no effect of drug and no interactions between variables. Post hoc analyses indicated that the effect of strain was due to a significant difference between $\mathrm{C} 3 \mathrm{H} / \mathrm{HeJ}$ and $\mathrm{DBA} / 2 \mathrm{~J}$ $(\mathrm{F}(1,33)=8.14, p=0.01)$, with $\mathrm{C} 3 \mathrm{H} / \mathrm{Hej}$ mice having the greatest component activity and DBA/2J the least. ERP responses for the individual strains (Figure 3 ) indicate that $\mathrm{C} 3 \mathrm{H} / \mathrm{HeJ}$ mice have the highest amplitude response at $150 \mathrm{~ms}$ and a broader trough at $40-50 \mathrm{~ms}$ than DBA/2J mice. The novel-standard difference reflected a higher mean \pm SD factor score for novel $(0.13 \pm 1.00)$ than standard $(-0.13 \pm 0.99)$. Given the orientation of compo- nent 2, this indicates that the overall ERP would be more positive at $150 \mathrm{~ms}$ following novel stimuli, independent of strain or drug state, and this is, in fact, what we observe (Figure 4).

The third component accounted for $21 \%$ of the variance, with maximal factor load values between 60 and $80 \mathrm{~ms}$ (Figure 2c). ANOVA performed on component 3 scores indicated a main effect for strain $(\mathrm{F}(2,33)=5.46, p<0.01)$, without significant effects of novelty or ketamine. This strain effect, again, reflected a significant difference between $\mathrm{C} 3 \mathrm{H} / \mathrm{HeJ}$ and $\mathrm{DBA} / 2 \mathrm{~J}$ mice $(\mathrm{F}(1,33)=10.92, p<0.01)$, with C57BL/6J being intermediate between but not significantly different from either of the other two. Mean + SD component 3 score for $\mathrm{C} 3 \mathrm{H} / \mathrm{HeJ}$ mice was negative $(-0.35 \pm 0.98)$, while that for DBA/2J mice was positive $(0.42 \pm 1.01)$. Evoked potentials from these strains (Figure 3 ) indicate that the amplitude of response in the ERP interval dominated by component 3 is more positive in $\mathrm{DBA} / 2 \mathrm{~J}$ than $\mathrm{C} 3 \mathrm{H} / \mathrm{HeJ}$ mice when averaged across all stimulus and drug conditions. Qualitative analysis of ERP waves suggests that DBA/2J (Figure $3 \mathrm{~b}$ ) and $\mathrm{C} 3 \mathrm{H} / \mathrm{HeJ}$ (Figure 3c) are similar in their N40 amplitudes. However, $\mathrm{DBA} / 2 \mathrm{~J}$ mice return to baseline by $60 \mathrm{~ms}$, while $\mathrm{C} 3 \mathrm{H} / \mathrm{HeJ}$ mice remain negative until approximately $80 \mathrm{~ms}$.

The fourth component accounted for $7.5 \%$ of the total variance and had maximum loadings between 12 and $22 \mathrm{~ms}$ (Figure 2d). ANOVA revealed a significant interaction between stimulus condition and ketamine administration $(\mathrm{F}(1,33)=5.62, p=0.02)$. Ketamine increased the amplitude of this component response to novel stimuli, while decreasing the response to standards. Although mean factor scores are relatively higher for the standard condition before ketamine, they are lower after ketamine administration. There was no significant effect of strain on component 4 .

\section{DISCUSSION}

This study demonstrates that mice display alterations in auditory-evoked potentials following novel stimuli and that 


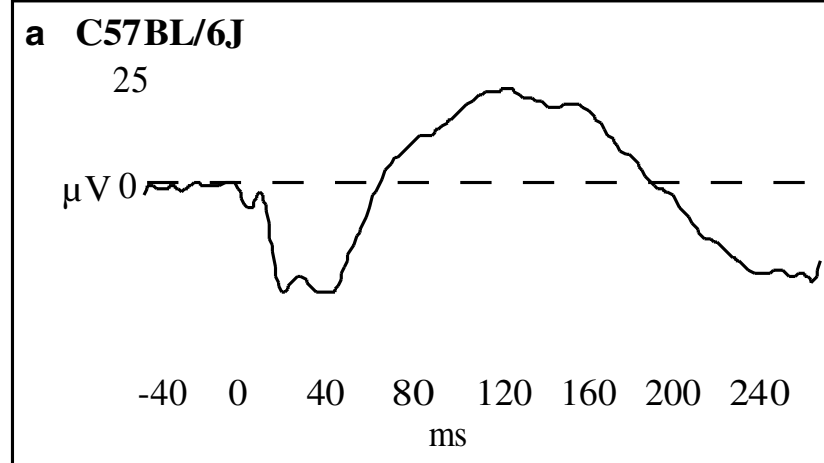

b DBA/2J

25

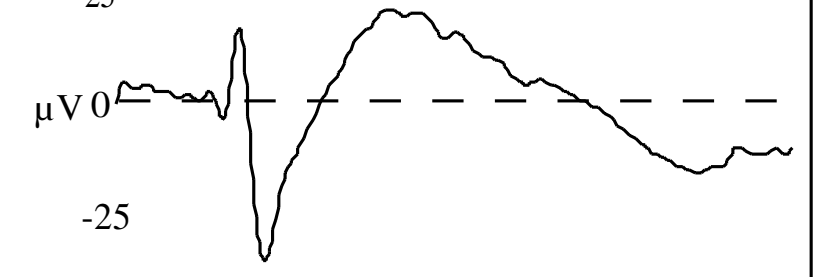

$\begin{array}{llllllll}-40 & 0 & 40 & 80 & 120 & 160 & 200 & 240\end{array}$ $\mathrm{ms}$

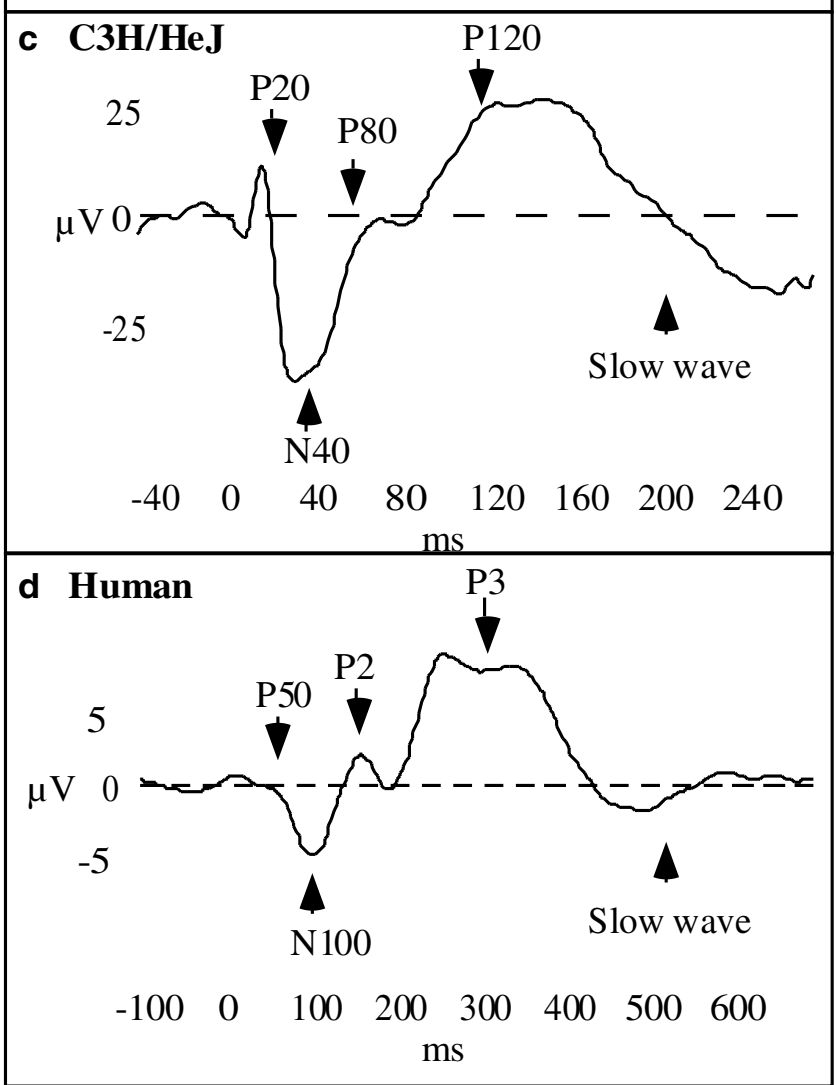

Figure 3 ERPs across all conditions for C57BL/6J (a), DBA/2J (b), and $\mathrm{C} 3 \mathrm{H} / \mathrm{HeJ}$ (c) mice. Additionally, an example of a human ERP averaged across stimulus type (novel and standard) is included to demonstrate the morphology of the human P50, NI00, P200, P300 and slow wave in relation to the mouse P20, N40, P80, PI 20 and slow wave. Note that the time scale for mice is $40 \%$ that in humans and the amplitude of evoked potentials is greater in mice due to the use of intracranial electrodes as compared to scalp electrodes in humans. a

Mouse Auditory Evoked Potential
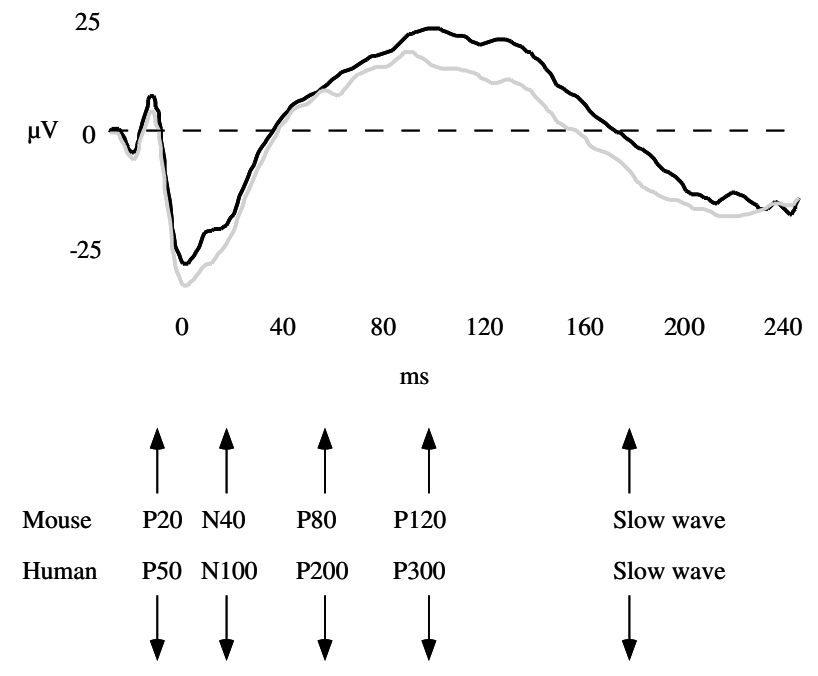

b

Human Auditory Evoked Potential

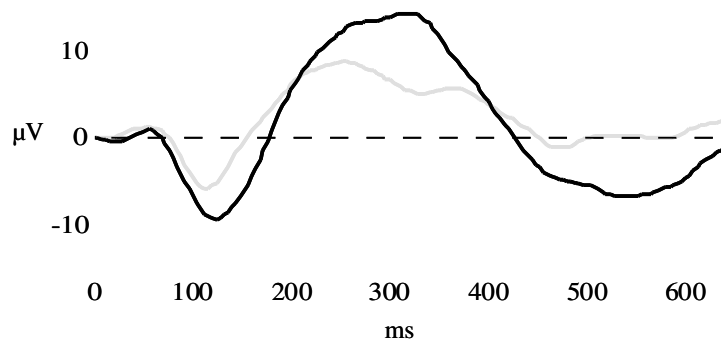

Figure 4 (a) Mouse ERP to novel (black) and standard (gray) across all strains and drug treatment conditions. (b) Human ERP responses to novel (black) and standard (gray). Note that the human P300 and mouse PI20 display increased amplitude following novel stimuli. As in Figure 3, the time scale for mice is $40 \%$ that in humans and the amplitude of evoked potentials is greater in mice due to the use of intracranial electrodes as compared to scalp electrodes in humans.

these novelty responses are strain dependent. People with schizophrenia, and many of their first-degree relatives, display deficits in novelty-evoked potentials making this ERP phenotype well suited to investigate the neurobiological and genetic contributions to the illness (Sams et al, 1985; Turetsky et al, 2000; Jessen et al, 2001; Michie, 2001). A mouse model of novelty-induced ERP components would facilitate not only the investigation of cellular mediators of impaired novelty-related ERPs, but would add the potential for analyses of genetic factors that contribute to these neurobiological mechanisms. Novelty-related ERP components are defined in humans based on their latency, orientation, and stimulus response properties (Spencer $e t$ $a l, 2001)$. These components include the mismatch negativity between 100 and $225 \mathrm{~ms}$, the P300 at approximately $300 \mathrm{~ms}$, and the slow wave at approximately $500 \mathrm{~ms}$ (Paavilainen et al, 1989; Alho et al, 1998; Ceponiene et al, 1998; Schall et al, 1999; Umbricht et al, 2000). We are not aware of previous studies describing novelty-related evoked potentials in mice. Therefore, the current study seeks to establish the latencies, orientations, and amplitudes for novelty-related ERP components in mice so that future studies can utilize mouse models to investigate neuropatho- 
logical and genetic factors that contribute to novelty-related ERP deficits in schizophrenia.

In order to use mice to investigate ERP abnormalities in schizophrenia, we must first establish which components in the mouse ERP correspond to the relevant ERP components in humans. As demonstrated in Figures 3 and 4, the human and mouse auditory ERP share similar overall morphology. The mouse P20 and N40 bear similarity to the human P50 and N100 in relative latency and orientation. Previous studies have shown that the mouse P20/N40 waveform is gated following repeated stimuli similar to the human P50 and N100 components (Siegel et al, 1984; Stevens et al, 1996; Boutros et al, 1999; Connolly et al, in review). Following the $\mathrm{N} 100$, the human ERP contains an automatic positive deflection at approximately $200 \mathrm{~ms}$ termed the P2 or P200 (Frodl et al, 1998). Similarly, the mouse auditory ERP contains a positive deflection at approximately $80 \mathrm{~ms}$ following the N40, which we have termed the P80 (Figures $3 \mathrm{c}$ and $4 \mathrm{a}$ ). After the P200, a novelty responsive component termed the P3 or P300 occurs in humans at approximately $300 \mathrm{~ms}$ (Ogura et al, 1991; Frodl et al, 1998). Similarly, the mouse P80 is followed by a peak that is augmented by novelty at approximately $120 \mathrm{~ms}$, which we have called the P120 (Figure 4a). Taken together, these data suggest that auditory ERP latencies in the mouse are approximately $40 \%$ of those seen in humans.

PCA analysis in the current study identifies four temporal components with morphological and response properties similar to the P20 (component 4, Figure 2d), the P80 (component 3, Figure 2c), the P120 (component 2, Figure $2 \mathrm{~b}$ ), and the slow wave (component 1, Figure 2a). Additionally, the N40 was distributed between PCA components 1 and 2 (Figure 2a and b). We propose that PCA components 4 and 3 represent the mouse P20 and P80, which we consider are mouse equivalents of the human P50 and P200. Consistent with this hypothesis, neither of these PCA components displayed a main effect for novelty. PCA component 1 is proposed to represent the slow wave with an additional contribution to the N40. This component displayed a novelty effect among $\mathrm{C} 3 \mathrm{H} / \mathrm{HeJ}$ mice, but not the other two strains. As such, this component supports the use of inbred strains of mice to model novelty-evoked potentials that have been proposed to have a genetic determinant (Schreiber et al, 1992; Turetsky et al, 1998b, 2000; Karoumi et al, 2000; Winterer et al, 2001).

Among all of the PCA components identified in this study, only component 2 showed a main effect of novelty that was independent of strain or drug. The peak latency of component 2 was between 120 and $150 \mathrm{~ms}$, consistent with a proposed mouse equivalent of the human P300 at $40 \%$ of the human latency. PCA component 2 may represent the mouse equivalent of the human P300, and subsequent investigations could analyze this portion of the mouse ERP for changes in amplitude with novelty. Furthermore, genetic and pharmacological manipulations could be examined for effects similar to P300 deficits in schizophrenia. Component 2 also showed a main effect for strain that was due to a difference between $\mathrm{C} 3 \mathrm{H} / \mathrm{HeJ}$ and DBA/2J mice. While there are no previous data regarding the P300 component in various strains of mice, there is a precedent for strain differences in other ERP components, including the P20/ $\mathrm{N} 40$ (Stevens et al, 1996). In the case of P20/N40 gating,
$\mathrm{C} 3 \mathrm{H} / \mathrm{He}$ mice display ERP profiles similar to healthy populations, while DBA/2 mice have lower levels of gating, similar to patients with schizophrenia (Stevens et al, 1996). The current study suggests that DBA/2J mice may also display a decreased P300-like component relative to $\mathrm{C} 3 \mathrm{H} /$ HeJ mice. Since people with schizophrenia have decreased P300 amplitudes, the current study suggests that DBA/2J and $\mathrm{C} 3 \mathrm{H} / \mathrm{HeJ}$ mice may serve as a useful model to understand differences in neuronal networks that mediate P300 responses in people with and without schizophrenia (Roth et al, 1980a b; Blackwood et al, 1987; Brecher et al, 1987; Pfefferbaum et al, 1989; Ford et al, 1992; Turetsky et al, 1998a,b). Additionally, component 1 exhibited an interaction between strain and novelty due to a difference in the response to novel and standard tones in $\mathrm{C} 3 \mathrm{H} / \mathrm{HeJ}$ mice, which was absent in the other two strains. When compared directly, C3H/HeJ mice differed from DBA/2J mice on this novelty-standard difference. These findings suggest that $\mathrm{C} 3 \mathrm{H} / \mathrm{HeJ}$ mice are able to mount distinct responses to novel and standard stimuli, while DBA/2J mice are not. Again, this is consistent with the hypothesis that $\mathrm{C} 3 \mathrm{H} / \mathrm{HeJ}$ mice possess a pattern of neuronal organization that allows for a greater degree of novelty detection than DBA/2J mice. To the degree that novelty detection has been shown to be impaired in people with schizophrenia, this is also consistent with the hypothesis that DBA/2J mice may serve as a useful model for the neuronal abnormalities that contribute to ERP deficits in this patient population.

The mismatch negativity following auditory pitch deviance occurs in humans at approximately $150 \mathrm{~ms}$. Therefore, we would expect to find a mouse equivalent of the mismatch negativity at approximately $60 \mathrm{~ms}$ based on a proposed latency of $40 \%$ that in humans. However, the current study does not identify a novelty-responsive PCA component to support the presence of mismatch negativity in the strains tested. This lack of mismatch negativity in the current study, as well as the lack of a ketamine effect on novelty detection, may be due to the relatively short interval of $24 \mathrm{~h}$ between electrode surgery and testing. This interval was chosen to minimize the effects of mechanical disruption due to chronic electrode implantation as well as the potential stress effects of isolation rearing during individual housing, which has been shown to alter ERPs in rats (Stevens et al, 1997). Additionally, previous data in our laboratory demonstrate that gating of the P20/N40-evoked potential is not altered in DBA/2 mice between 1 and 7 days following surgery (Connolly et al, in review), and preliminary studies in our laboratory indicate that novelty detection is not altered in any of the PCA components in DBA/2 mice between 1 and 7 days following surgery. While previous studies of gating of P20/N40-evoked potentials in mice have utilized anesthetized animals, the methods developed in the current study allow for nonanesthetized recording of evoked potentials in mice (Stevens et al, 1996; Stevens and Wear, 1997; Simosky et al, 2001). Future studies could investigate potential interactions between postoperative interval and novelty detection among various strains of mice to further examine the possibility that mismatch negativity was masked in the current design.

An animal model of novelty-related potentials could also facilitate evaluation of the anatomic localization of specific components in ways not possible in humans. The majority 
of evidence indicates that the cerebral generator for the P300 originates within the primary auditory cortex, with additional contributions from the hippocampus, thalamus, and prefrontal cortex (Ruusuvirta et al, 1995; Alho et al, 1998). Data presented within this initial study of noveltyevoked responses in mice utilized bipolar recording of field potentials between a neocortical and hippocampal location, precluding the ability to localize specific generators. However, future studies could examine the independent contributions to novelty-related evoked potentials from individual cerebral locations.

In summary, the present study suggests that ERP components in the mouse occur at approximately $40 \%$ of the latency in humans. These consist of the previously described P20 and N40 components, which we propose to represent the P50 and N100, respectively. Additionally, we describe an automatic evoked potential that does not respond to novelty, which we have called the $\mathrm{P} 80$, and that is similar to the human P200. We also describe a mouse equivalent of the P300 at approximately $120 \mathrm{~ms}$, which we call the P120, and a novelty-responsive slow wave component at approximately $240 \mathrm{~ms}$. Lastly, we describe differences among inbred strains for several of these evoked components that support the use of $\mathrm{C} 3 \mathrm{H} / \mathrm{HeJ}$ and $\mathrm{DBA} / 2 \mathrm{~J}$ mice as models for patterns of neuronal organization that underlie abnormalities in evoked potentials among people with schizophrenia and their first-degree relatives.

\section{ACKNOWLEDGEMENTS}

The work was carried out in the Departments of Psychiatry and Biostatistics and Epidemiology, University of Pennsylvania, Philadelphia, PA. This work was supported by The Theodore and Vada Stanley Foundation Research Award (SJS) and the Kempf Fund Award from the American Psychiatric Association (SJS, REG) and NIH P50-MH64045 (REG). The authors do not have any financial interests or links to industry that are related to the material contained within this manuscript.

\section{REFERENCES}

Alho K, Winkler I, Escera C, Huotilainen M, Virtanen J, Jaaskelainen IP et al (1998). Processing of novel sounds and frequency changes in the human auditory cortex: magnetoencephalographic recordings. Psychophysiology 35: 211-224.

Bentler PM, Yuan KH (1996). Test of linear trend in eigenvalues of a covariance matrix with application to data analysis. $\mathrm{Br}$ J Math Stat Psychol 49: 299-312.

Blackwood DH, Whalley LJ, Christie JE, Blackburn IM, St Clair DM, McInnes A (1987). Changes in auditory P3 event-related potential in schizophrenia and depression. Br J Psychiatry 150: $154-160$

Boutros NN, Belger A, Campbell D, D’Souza C, Krystal J (1999). Comparison of four components of sensory gating in schizophrenia and normal subjects: a preliminary report. Psychiatry Res 88: 119-130.

Brecher M, Porjesz B, Begleiter H (1987). The N2 component of the event-related potential in schizophrenic patients. Electroencephalogr Clin Neurophysiol 66: 369-375.

Cattell RB (1966). The scree test for the number of factors. Multivariate Behav Res 1: 245-276.
Catts SV, Shelley AM, Ward PB, Liebert B, McConaghy N, Andrews $S$ et al (1995). Brain potential evidence for an auditory sensory memory deficit in schizophrenia. Am J Psychiatry 152: 213-219.

Ceponiene R, Cheour M, Naatanen R (1998). Interstimulus interval and auditory event-related potentials in children: evidence for multiple generators. Electroencephalogr Clin Neurophysiol 108: 345-354.

Connolly PM, Kanes SJ, Abel EG, Liang Y, Maxwell C, Tokarczyk J et al (in review). Auditory evoked potentials, startle and prepulse inhibition in DBA/2J and DBA/2Hsd inbred mouse substrains.

Escera C, Alho K, Winkler I, Naatanen R (1998). Neural mechanisms of involuntary attention to acoustic novelty and change. J Cogn Neurosci 10: 590-604.

Ford JM, Hillyard SA (1981). Event-related potentials (ERPs) to interruptions of a steady rhythm. Psychophysiology 18: 322-330.

Ford JM, Pfefferbaum A, Roth W (1992). P3 and schizophrenia. Ann NY Acad Sci 658: 146-162.

Freedman R, Adler LE, Waldo MC, Pachtman E, Franks RD (1983). Neurophysiological evidence for a defect in inhibitory pathways in schizophrenia: comparison of medicated and drug-free patients. Biol Psychiatry 18: 537-551.

Frodl T, Meisenzahl EM, Gallinat J, Hegerl U, Moller HJ (1998). Markers from event-related potential subcomponents and reaction time for information processing dysfunction in schizophrenia. Eur Arch Psychiatry Clin Neurosci 248: 307-313.

Grzella I, Muller BW, Oades RD, Bender S, Schall U, Zerbin D et al (2001). Novelty-elicited mismatch negativity in patients with schizophrenia on admission and discharge. J Psychiatry Neurosci 26: $235-246$.

Javitt DC, Doneshka P, Zylberman I, Ritter W, Vaughan Jr HG (1993). Impairment of early cortical processing in schizophrenia: an event-related potential confirmation study. Biol Psychiatry 33: 513-519.

Javitt DC, Steinschneider M, Schroeder CE, Arezzo JC (1996). Role of cortical $\mathrm{N}$-methyl-D-aspartate receptors in auditory sensory memory and mismatch negativity generation: implications for schizophrenia. Proc Natl Acad Sci USA 93: 11962-11967.

Jessen F, Fries T, Kucharski C, Nishimura T, Hoenig K, Maier W et al (2001). Amplitude reduction of the mismatch negativity in first-degree relatives of patients with schizophrenia. Neurosci Lett 309: 185-188.

Karoumi B, Laurent A, Rosenfeld F, Rochet T, Brunon AM, Dalery $J$ et al (2000). Alteration of event related potentials in siblings discordant for schizophrenia. Schizophr Res 41: 325-334.

Leonard S, Adams C, Breese CR, Adler LE, Bickford P, Byerley W et al (1996). Nicotinic receptor function in schizophrenia. Schizophr Bull 22: 431-445.

Mathalon DH, Ford JM, Pfefferbaum A (2000). Trait and state aspects of P300 amplitude reduction in schizophrenia: a retrospective longitudinal study. Biol Psychiatry 47: 434-449.

Michie PT (2001). What has MMN revealed about the auditory system in schizophrenia? Int J Psychophysiol 42: 83-100.

Ogura C, Nageishi Y, Matsubayashi M, Omura F, Kishimoto A, Shimokochi M (1991). Abnormalities in event-related potentials, N100, P200, P300 and slow wave in schizophrenia. Jpn J Psychiatry Neurol 45: 57-65.

Paavilainen P, Karlsson ML, Reinikainen K, Naatanen R (1989). Mismatch negativity to change in spatial location of an auditory stimulus. Electroencephalogr Clin Neurophysiol 73: 129-141.

Pfefferbaum A, Ford JM, White PM, Roth WT (1989). P3 in schizophrenia is affected by stimulus modality, response requirements, medication status, and negative symptoms. Arch Gen Psychiatry 46: 1035-1044.

Pincze Z, Lakatos P, Rajkai C, Ulbert I, Karmos G (2001). Separation of mismatch negativity and the $\mathrm{N} 1$ wave in the auditory cortex of the cat: a topographic study. Clin Neurophysiol 112: 778-784. 
Roth WT, Horvath TB, Pfefferbaum A, Kopell BS (1980a). Eventrelated potentials in schizophrenics. Electroencephalogr Clin Neurophysiol 48: 127-139.

Roth WT, Pfefferbaum A, Horvath TB, Berger PA, Kopell BS (1980b). P3 reduction in auditory evoked potentials of schizophrenics. Electroencephalogr Clin Neurophysiol 49: 497-505.

Roth WT, Pfefferbaum A, Kelly AF, Berger PA, Kopell BS (1981). Auditory event-related potentials in schizophrenia and depression. Psychiatry Res 4: 199-212.

Ruusuvirta T (1999). From spatial acoustic changes to attentive behavioral responses within $200 \mathrm{~ms}$ in humans. Neurosci Lett 275: 49-52.

Ruusuvirta T, Korhonen T, Penttonen M, Arikoski J, Kivirikko K (1995). Hippocampal event-related potentials to pitch deviances in an auditory oddball situation in the cat: experiment I. Int $J$ Psychophysiol 20: 33-39.

Sams M, Alho K, Naatanen R (1983). Sequential effects on the ERP in discriminating two stimuli. Biol Psychol 17: 41-58.

Sams M, Paavilainen P, Alho K, Naatanen R (1985). Auditory frequency discrimination and event-related potentials. Electroencephalogr Clin Neurophysiol 62: 437-448.

Schall U, Catts SV, Karayanidis F, Ward PB (1999). Auditory eventrelated potential indices of fronto-temporal information processing in schizophrenia syndromes: valid outcome prediction of clozapine therapy in a three-year follow-up. Int J Neuropsychopharmcol 2: 83-93.

Schreiber H, Stolz-Born G, Kornhuber HH, Born J (1992). Eventrelated potential correlates of impaired selective attention in children at high risk for schizophrenia. Biol Psychiatry 32: 634651.

Shelley AM, Ward PB, Catts SV, Michie PT, Andrews S, McConaghy N (1991). Mismatch negativity: an index of a preattentive processing deficit in schizophrenia. Biol Psychiatry 30: 1059-1062.

Siegel C, Waldo M, Mizner G, Adler LE, Freedman R (1984). Deficits in sensory gating in schizophrenic patients and their relatives. Arch Gen Psychiatry 41: 607-612.
Siegel SJ, Lenox RH, Gur RE, Turetsky BI (2001). Sensory gating and mismatch negativity in schizophrenia and mice. Proc Soc Neurosci.

Simosky JK, Stevens KE, Kem WR, Freedman R (2001). Intragastric DMXB-A, an alpha7 nicotinic agonist, improves deficient sensory inhibition in DBA/2 mice. Biol Psychiatry 50: 493-500.

Spencer KM, Dien J, Donchin E (2001). Spatiotemporal analysis of the late ERP responses to deviant stimuli. Psychophysiology 38: 343-358.

Stevens KE, Freedman R, Collins AC, Hall M, Leonard S, Marks M] et al (1996). Genetic correlation of inhibitory gating of hippocampal auditory evoked response and $\alpha$-bungerotoxinbinding nicotinic cholinergic receptors in inbred mouse strains. Neuropsychopharmacology 15: 152-162.

Stevens KE, Johnson RG, Rose GM (1997). Rats reared in social isolation show schizophrenia-like changes in auditory gating. Pharmacol Biochem Behav 58: 1031-1036.

Stevens KE, Wear KD (1997). Normalizing effects of nicotine and a novel nicotinic agonist on hippocampal auditory gating in two animal models. Pharmacol Biochem Behav 57: 869-874.

Turetsky BI, Cannon TD, Gur RE (2000). P300 subcomponent abnormalities in schizophrenia: III. Deficits in unaffected siblings of schizophrenic probands. Biol Psychiatry 47: 380-390.

Turetsky B, Colbath EA, Gur RE (1998a). P300 subcomponent abnormalities in schizophrenia: II. Longitudinal stability and relationship to symptom change. Biol Psychiatry 43: 31-39.

Turetsky BI, Colbath EA, Gur RE (1998b). P300 subcomponent abnormalities in schizophrenia: I. Biol Psychiatry 43: 84-96.

Umbricht D, Schmid L, Koller R, Vollenweider FX, Hell D, Javitt DC (2000). Ketamine-induced deficits in auditory and visual context-dependent processing in healthy volunteers: implications for models of cognitive deficits in schizophrenia. Arch Gen Psychiatry 57: 1139-1147.

Winterer G, Egan MF, Radler T, Coppola R, Weinberger DR (2001). Event-related potentials and genetic risk for schizophrenia. Biol Psychiatry 50: 407-417. 